\title{
THE EFFECT OF ACETONE AS A POST-PRODUCTION FINISHING TECHNIQUE ON ENTRY-LEVEL MATERIAL EXTRUSION PART QUALITY
}

\author{
S.P. Havenga ${ }^{1 *}$, D.J. de Beer ${ }^{2}$, P.J.M. van Tonder $^{1}$ \& R.I. Campbell ${ }^{1}$
}

\section{ARTICLE INFO}

\section{Article details}

Submitted by authors 20 Feb 2018 Accepted for publication 17 Sep 2018 Available online $\quad 10$ Dec 2018

\section{Contact details}

* Corresponding author sarelh@vut.ac.za

Author affiliations

1 Department of Technology Transfer and Innovation, Vaal University of Technology, Vanderbijlpark, South Africa

2 DST Chair: Innovation and Commercialisation of Additive Manufacturing, Centre for Rapid Prototyping and Manufacturing, Central University of Technology, Free State, Bloemfontein, South Africa

DOI

http://dx.doi.org/10.7166/29-4-1934

\section{ABSTRACT}

Entry-level material extrusion artefacts persistently suffer from questionable weakened end-product production quality, according to industrial standards. These limitations can be addressed by the development of improved finishing techniques that may narrow the gap between low-cost and high-end production methods in additive manufacturing. In doing so, the technology may become available to a larger spectrum of prosumers who previously were reluctant to use entry-level technology because of these limitations. This article describes the effect that acetone has as a post-production finishing technique for low-cost artefact production. Through a series of quantitative investigations, the study provides evidence that acetone reduces the tensile strength, increases polymer ductility, and significantly reduces the surface profile roughness of thermoplastics such as acrylonitrile butadiene styrene. The potential cost and waste reduction for entry-level manufactured products can then be identified.

\section{OPSOMMING}

Intreevlak materiaal ekstrusie modelle word tans, volgens industriële standaarde, deur verswakte eindproduk produksiekwaliteit benadeel. Hierdie tekortkominge kan deur die ontwikkeling van verbeterde afwerkingstegnieke aangespreek word. Sodoende kan die gaping tussen intree- en hoë-vlak laagvervaardiging vernou word. Meer gebruikers wat voorheen onwillig was om die tegnologie as gevolg van tekortkominge te gebruik, kan nou toegang verkry daartoe. Die artikel bespreek die impak wat asetoon as post-produksie afrondingsmiddel vir lae-koste produksie kan bewerkstellig. Deur 'n reeks kwantitatiewe ondersoeke bewys die artikel dat asetoon die treksterkte van akrylonitrilbutadienestyrene (ABS) verswak, die polimeriseerbaarheid daarvan versterk, en die oppervlak profiel ruheid drasties verminder. Potensiële koste en afvalvermindering kan dus hierdeur vir intreevlak vervaardigde produkte geïdentifiseer word.

\section{INTRODUCTION}

Entry-level material extrusion (ELME) development is experiencing a notable growth in the opensource makerspace and in the academic sphere. The growth in these open creative spaces where designers, engineers, and prosumers fabricate is mainly attributed to hardware (3D printer) and software (CAD program) developments. 'Prosumers' have become defined as consumers of the production materials used during the fabrication of $3 \mathrm{D}$ printed artefacts. It is, however, evident that although ELME is improving, there are quality limitations to the technology. Experimental techniques have emerged in the open-source 3D printing marketplace to address these limitations (based on evidence found in online blogs and vlogs), but very little academic involvement and documentation have been recorded [7, 16]. As recently as three years ago, insufficient data were available to 
provide a formal platform for referencing or citing the development of post-production finishing techniques (PPFTs) for ELME.

The aim of this study was to explore the use and effectiveness of organic solvent compounds in different post-processing investigations, to improve on the fabrication limitations found in ELME. In addition, it also attempted to identify potential methods for the successful development of ELME post-production on an increased fabrication scale in the additive manufacturing (AM) market.

A pre-experimental study was first conducted to investigate possible techniques that could be used for post-production finishing to optimise the choice of reactive solvents. It consisted of testing experimental techniques obtained from online sources via maker blogs, engineering-specific additive manufacturing, and fine-art techniques [13]. Acetone was identified as an important candidate substance due to its reaction with thermoplastics such as acrylonitrile butadiene styrene (ABS) and polylactic acid (PLA). Quantitative data were then collected to provide a comprehensive view on the merit of acetone use in PPFTs. It was important to compare the production and post-production phases in a systematic way, starting with tensile strength properties, followed by surface roughness properties and then ductility. Finally, a supplementary lead-time comparison was investigated.

There is a need for improved manufacturing techniques and to make sense of the context in which limitations, in the current technology exist; the authors sketch a picture of the scope of the problems encountered, in a local and global setting.

Material extrusion is used worldwide, but is limited mostly to the low-cost market. As early as 2002, research produced evidence of material extrusion limitations such as 'stair-stepping' [1]. Often the answer to these limitations is sought through fabrication or hardware modifications, rather than by identifying potential post-processing solutions $[1,5,7,9,12,18,21]$.

Unfortunately, disadvantages in the form of step-layering (stair-stepping) and print-size limitations delay the development and implementation of ELME, not only in developing countries like South Africa, but worldwide. In Europe these limitations are addressed by considering production methods such as the print part-orientation [7]. One possible avenue of investigation into improving manufacturing productivity, is to focus on developing hard-skills such as finishing techniques during post-processing, rather than being hampered by hardware and production limitations.

In South Africa, ELME is used to introduce low-cost additive manufacturing through 3D printing laboratories to any person with sufficient interest. Academic initiatives, such as the Idea2Product $\AA$ $(I 2 P \circledast)$ laboratories, provide a platform where ELME can be practised through CAD design and 3D printing training to any interested person [5]. This initiative originated at the Vaal University of Technology in Vanderbijlpark, South Africa, during 2011, due to a local need for skills development and forms part of what is known as the 'Roadmap to Rapid Prototyping in South Africa' [2, 3].

Similarly, projects like RepRap are credited for the development and expansion of entry-level fused filament fabrication (FFF), which is similar to the fused deposition modeling ${ }^{1}$ (FDM) concept $[4,6]$. These fabrication laboratories are the ideal open-source platforms for the development of and experimentation with techniques, as they allow a much wider spectrum of users to be exposed to entry-level additive manufacturing processes at a fraction of the cost of conventional high-end material extrusion (HEME).

Some researchers have begun to recognise the need for post-processing due to persistent occurrences of limitations not being resolved. Galantucci [8] is one who acknowledges the use of acetone as a PPFT to address surface defects.

This raises the question: Why are ELME limitations predominantly being addressed through production-phase research rather than by post-processing methods, such as acetone finishing? Tanikella postulates that the concept of decentralised manufacturing is possible with home-based $3 D$ printing in both developing and developed countries $[16,17,19]$. Previous studies have shown that such forms of manufacturing allow not only a lower cost of goods for the consumer [22], but

1 Note to reader: Although 'modelling' is usually spelled with a double 'l' in South Africa, the first author makes use here of the spelling in the trademarked version, 'fused deposition modeling' (FDM), by 
also a reduced negative environmental impact, such as from pollution and production waste [10, 11 , 17]. It is therefore important to develop ELME; and, where the technology reaches a production developmental ceiling, acetone post-production finishing techniques would be the next logical step for the low-cost 3D printing industry.

\section{METHODOLOGY}

This paper is grounded in literature reviews combined with quantitative research investigations. The latter were conducted to provide empirical data to record the influence that acetone has on ELME thermoplastics such as ABS and PLA.

To determine the effect that acetone has on thermoplastics, it is important to establish what influence it has on their mechanical property appearance, which materials are affected, and the surface profile of exposed specimens; and to compare the respective production lead times. Our account of the experimental research methods used was therefore separated into three parts: methods, material, and instrumentation.

\subsection{Methods}

The initial experimental method involved a pilot study to identify possible techniques to postprocess ELME components. Acetone was identified as a promising chemical to investigate on ABSproduced ELME components due to its visually observed influence on the thermoplastic. This method of investigation was qualitative in nature, without empirical data. It was therefore largely based on assumptions made from visual observations, and led to questions that formed the basis for a quantitative research paradigm.

An investigative quantitative procedure was followed next, to identify methods of testing the effects of acetone as a chemical on various thermoplastics (ABS, PLA, and other experimental materials). To gain more substantial empirical data, we decided to investigate the tensile properties of the plastics and how the surface profile of each was affected by acetone. An acetone vapour chamber was employed to disperse the chemical evenly on to the specimen surface in each case.

Initially, limited instrumentation was available to the researchers to investigate tensile properties, so some adaptation was necessary to investigate the specimens. A Monsanto manual tensometer was used. Thereafter, more accurate and up-to-date instrumentation (Instron tensometers) were used by applying the ISO 527-2:2012 SABS test standard for thermoplastic extrusion [20]. The same standard was used to identify the correct specimen specifications. Various quantitative data sets were collected over a period of two years in both South Africa and the United Kingdom by the first author. Specific controls, such as the type of dog-bone specimen, exposure time, load cell, amount of acetone, and type of exposure were established to monitor the variables, and were then interpreted by comparing them with the corresponding literature $[19,20]$. The same controls were used on all the extrusion material specimens.

The last method of investigation was to assimilate all the data collected into a cohesive quantitative set of observations that address the notion of using acetone as a PPFT.

\subsection{Materials}

During the pre-experimental pilot study, a set of exposure materials was chosen, for three reasons. The first was a choice of materials used by online blog-makers; the second was industrial application; and the third was the first author's research background. The materials chosen were acetone, abrasive sanding paper, oil paint, aerosol spray paint, cyanoacrylate, spot-putty, DIY filler paste, plaster of Paris, wood glue and epoxy resin. All exposure materials were applied to various 3D printed specimens to investigate the influence they had on the physical quality and mechanical properties of the specimens.

Acetone was the only exposure material that affected some of the thermoplastic specimens both favourably and adversely. For this reason, all specimens were thereafter extensively investigated in relation to their exposure to acetone. These experiments were duplicated at different laboratories to compare and corroborate the results. All specimens tested were new filament rolls, extruded 
within 12 hours of being opened. The specimens were also exposed to chemical treatment within 48 hours of production, and tensile tested within 72 hours from their filament state.

In addition to the standard experiments, a need arose to compare the traditional extrusion materials with the new experimental extrusion blended materials that were developed by Tiertime, the official UP filament supplier. The authors decided to include these results, as they indicate the latest advances in the field. These additional extrusion filaments included UV reactive, glow-in-thedark, heat-reactive and nylon alloy extrusion materials.

For the sake of reporting on all the materials used during the study, it is important to clarify the abbreviations and words that will be used in the results section of this paper. Where a specific colour is referred to - for example, black or white - it indicates the colour of the specified extrusion polymer. 'Traditional material' refers to the original blend of extrusion material. Where the word 'plus' or the symbol $(+)$ is used, it refers to the latest copolymer blend of materials that are enhanced in colour, consistency, or tensile properties. The letter ' $A$ ' after the material's name is commonly used to refer to acetone exposure applied to that extrusion material. Furthermore, the names of the materials are abbreviated; for example, black will appear as BK in the graphs. Where the material has been enhanced to the new or improved material, the word 'black' will have a plus $\left(^{+}\right)$after it. In the graphs it will then be indicated as BK+. Where such a material has been exposed to acetone, it will have an 'A' added at the end, thus appearing as BK+A in abbreviated form.

Where a specific experimental extrusion material has been used, it is indicated by its registered industrial title - for example, 'Sunburst Chameleon ABS'. It will then be abbreviated to SUN in the graph and, where exposed to acetone, the letter ' $A$ ' will be added - for example, SUN A. Please refer to this section or consult the caption of each figure for greater clarity.

\subsection{Instrumentation}

\subsubsection{Tensile testing instruments}

Initial experiments were conducted using a Monsanto W-type manual tensometer on dog-bone specimens. Thereafter, new specimens were produced and tested at Loughborough University, UK on an Instron tensometer. A follow-up comparison was conducted, as the controls for the first Loughborough tests were different from those done in the initial experiments. The specimens were produced on an Ultimaker 3D printer with a material different in composition from that of the Tiertime supplier. The results for the acetone exposure on the ABS material were similar to the original results, although the latter material had increased tensile strength. The second set of specimens demonstrated more consistent results. These specimens were tested on an Instron tensometer, and a report was given during the RAPDASA 2015 conference [9].

The improved experimental materials were tested at the Centre for Rapid Prototyping and Manufacturing (CRPM) at the Central University of Technology (CUT) in Bloemfontein, South Africa, on an MTS Criterion 43 tensometer. The software was MTS Elite; no extensometer was used. All other specimens were produced on a UP MINI 3D printer.

\subsubsection{Surface roughness tester}

In previous studies reported by the first author [9], there were two methods of collecting surface roughness measurements. The first involved using a surface roughness tester to obtain quantitative arithmetical mean roughness $(\mathrm{Ra})$ and ten-point mean roughness $(\mathrm{Rz})$ readings to establish the influence of acetone on the surface texture. The second was to record qualitative observations by microscope and thereby interpret the effect that acetone had on the surface by infiltration and molecular restructuring. For the surface roughness tests, a Mitutoyo Surface Gauge SJ210 and a Techgear Eaglescope digital microscope were employed to observe and document the influence of acetone. The qualitative results of the microscopic observations are not discussed here. The improved and experimental materials were tested on a Dobamoni surface roughness tester.

\section{RESULTS}

The following results indicate the effect of chemical intervention on the surface roughness and mechanical properties of experimental specimens after post-production exposure. 


\subsection{Tensile strength properties}

The first tensile strength experiments were conducted on six black and white ABS and ABS+ extruded specimens, the results of which are shown in Figure 1. The red graph indicates control specimens. They represent white, black and black+ specimens. The green/blue graph lines illustrate the acetone-exposed specimens. They were white with acetone, black with acetone and black plus (+) with acetone. When advanced ABS+ specimens were compared with the regular acetone-treated ABS specimens, it was evident that the tensile strength and the extension had been reduced. The tensile strength of the white ABS specimens decreased by forty-nine per cent; that of black ABS declined by seven per cent; and black ABS+ by fifty-four per cent, corresponding to an overall tensile strength decline of thirty-eight per cent for the acetone exposed specimens.

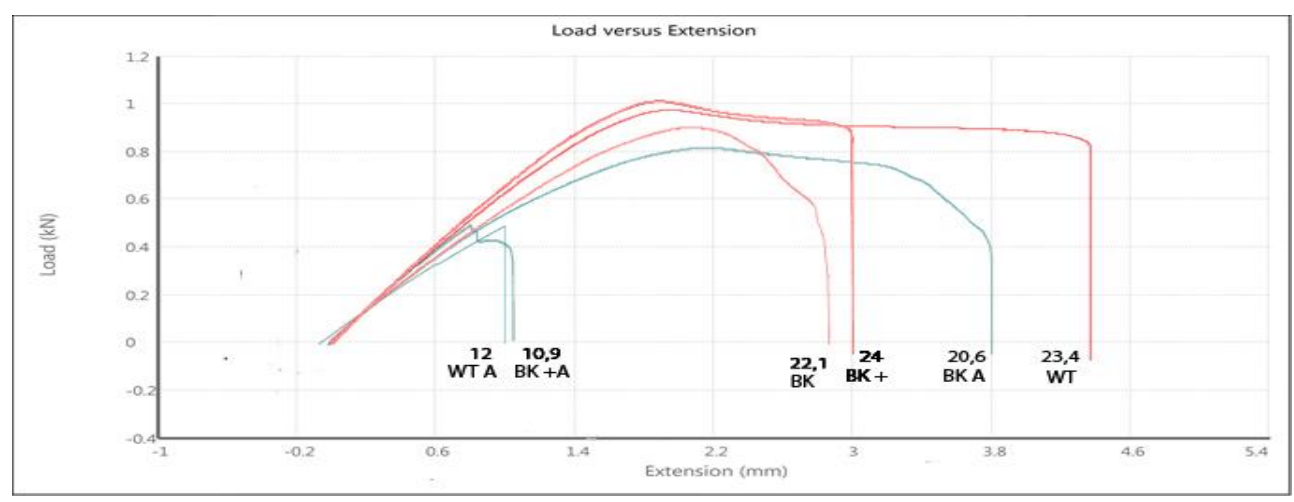

Figure 1: Effect of acetone on tensile strength properties in relation to extension for various black and white ABS and ABS+ ELME specimens. The UTS values are shown in bold at the end of the corresponding graph line. Legend: WT, white; BK, black; +, plus material property; A, exposed to acetone. Previous experiments done by the researcher during 2015 yielded similar results and therefore a larger specimen set was not needed [9].

The second set of tensile experiments illustrated that the Ultimate Tensile Strength (UTS) values of the experimental materials were less than those of the corresponding ABS specimens in Figure 2 below. The red graph lines in the figure indicate control specimens. They represent Sunburst Chameleon ABS, Glow Pacific Blue ABS and UV33 Fluro Chameleon ABS. The green/blue graph lines represent similar materials, but all exposed to acetone. The UTS of the Sunburst ABS material decreased by four per cent when exposed to acetone; the UV33 ABS declined by thirteen per cent; the Pacific Blue ABS declined by six per cent; and the UTS declined less obviously (by an overall eight per cent) than the traditional blended ABS results, but was still evident, as indicated by the green lines.

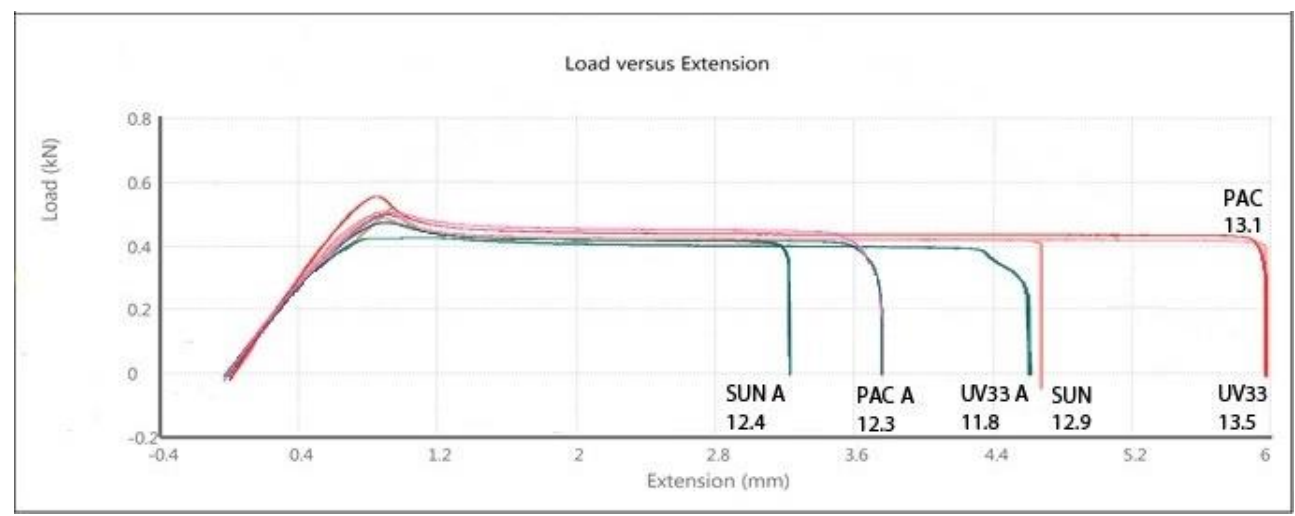

Figure 2: Effect of acetone exposure on tensile strength in relation to extension for various experimental specimens. The UTS is indicated in bold at the end of each corresponding graph line. Legend: SUN, Sunburst Chameleon ABS; PAC, Glow Pacific Blue ABS; UV33, Fluro Chameleon ABS; A, exposed to acetone. 
A third set of tensile experiments illustrated the effect that acetone has on PLA specimens. The red graph lines correspond to control specimens. This is demonstrated in Figure 3, which indicates the UTS values of the acetone-exposed PLA specimens. It is contrasting in nature, as it reflects opposing behaviour, as seen in ABS specimens in Figure 1. One black and one white specimen are illustrated by the green/blue graph line. The red graph line illustrates one black and white specimen that were exposed to acetone vapour. The UTS of the white PLA increased by zero-point-three per cent and the black PLA increased its UTS by eight per cent. This time, the red graph lines marked WT A and BK A indicate a clear average increase of four per cent in the PLA UTS.

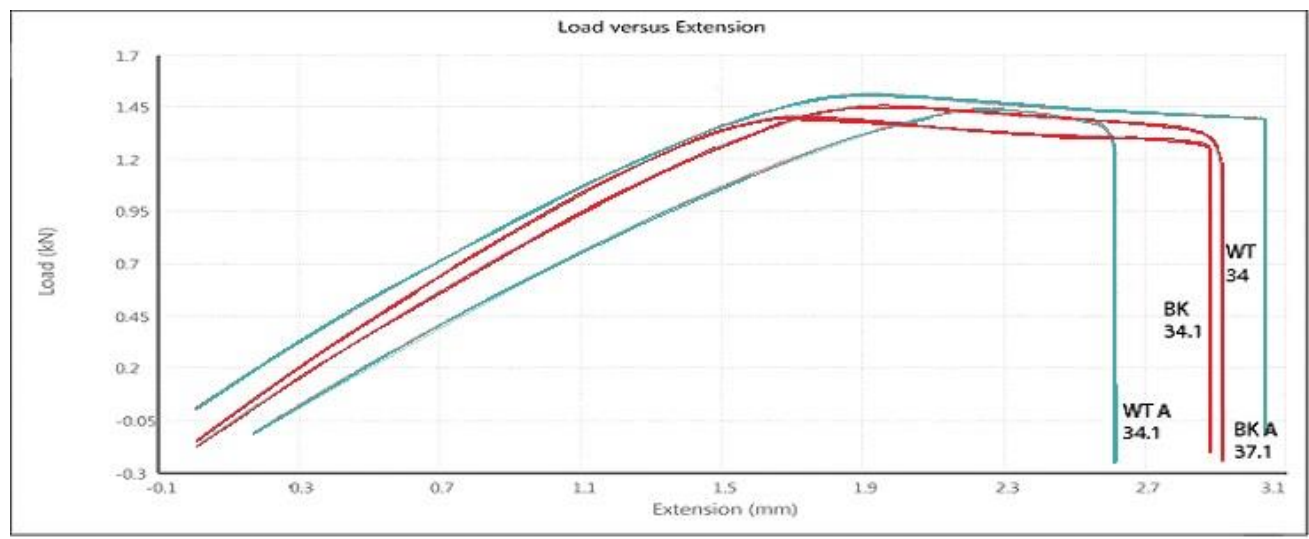

Figure 3: Effect of acetone exposure on tensile strength in relation to the extension recorded in PLA specimens. The UTS values are shown in bold at the end of the corresponding graph

line. Legend: WT, white; BK, black; A, exposed to acetone. The red lines in the graph correspond to the control specimens. The blue/green lines illustrate the acetone-exposed specimens.

A fourth set of tensile experiments illustrate how the co-polymer material blend Nylon Alloy was affected by acetone exposure (Figure 4). Only two specimens were examined due to the experimental nature of the material. The UTS of the specimens declined by nine per cent. The green graph line shows that the acetone-exposed nylon specimen had an erratic elongation path, pointing to the instability of the thermoplastic after acetone exposure. The red graph line shows the control nylon specimen and the green graph line shows the acetone exposed nylon specimen.

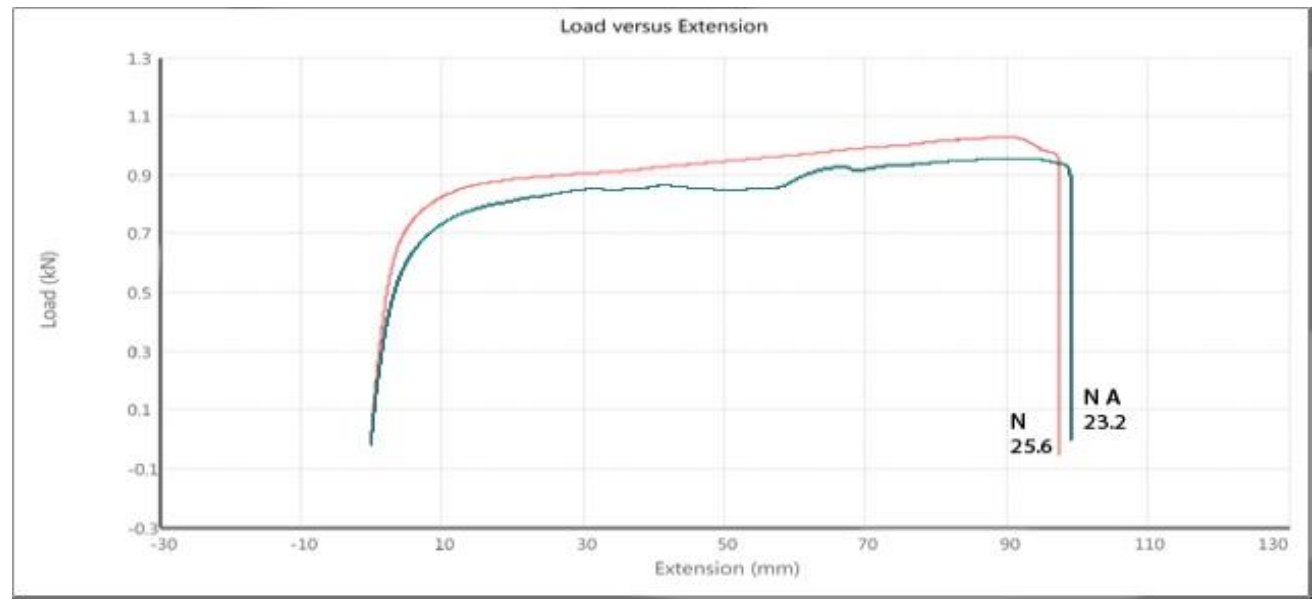

Figure 4: Effect of acetone exposure on the tensile strength of nylon specimens. The UTS values $(\mathrm{kN})$ are indicated in bold at the end of the corresponding graph line. Legend: $\mathrm{N}$, nylon; $\mathrm{N}$ A, nylon exposed to acetone. As only two specimens were tested for comparison with other experimental materials, readers should note that the above results might not reflect an accurate statistical representation. 
Figure 5 illustrates the overall trend of acetone effectiveness on the UTS measurements of all the specimens tested. The greatest influence on UTS was demonstrated by the PLA specimens, followed by the nylon alloy, then the improved $A B S$ and lastly the experimental $A B S$.

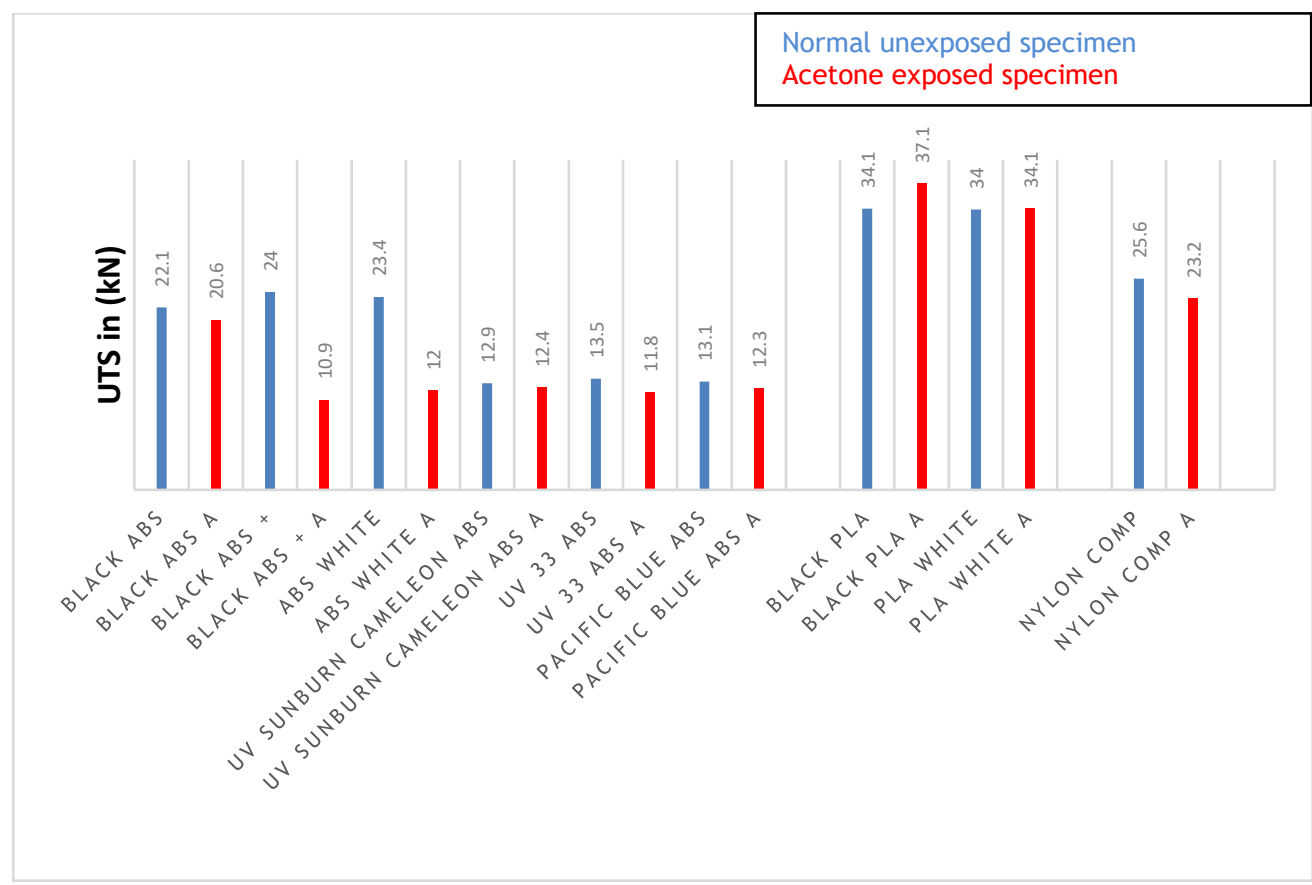

Figure 5: Effect of acetone on the ultimate tensile strength of various specimens. The graph illustrates from left the control specimen, followed by the acetone exposed specimens.

Legend: A, acetone exposed specimen. The data entries (bars) along the $x$-axis show the UTS values of the various specimens in pairs, comprising a control to the left and effect of acetone exposure on the right: for example, the two extreme left hand entries show the UTS for black $A B S$ and, to its right, that for the acetone exposed black ABS A. (see online version for colour)

\subsection{Ductility}

Acetone exposure influenced the ductility of the ABS specimens, as seen in Figure 6. The standard ABS specimens elongated by 1.97 per cent. When treated with acetone, elongation was 2.84 per cent, a relative increase of forty-four per cent $\{(2,84-1,97) \div 1,97\} \times 100$. For the final tested experimental $A B S$, a trend similar to that seen above was observed. An elongation of 5.4 per cent was observed for the ABS, but when exposed to acetone it increased by seventy-seven per cent.

The new PLA elongated by 0.5 per cent, and increased to 0.85 per cent when the specimen was exposed to acetone.

It is noteworthy that there was little difference between the entry-level materials and the high-end materials in respect of elongation. Entry-level $A B S$ averaged a $1.88 \mathrm{~mm}$ increase at the breaking point. PLA averaged a $1.96 \mathrm{~mm}$ elongation at the breaking point. 


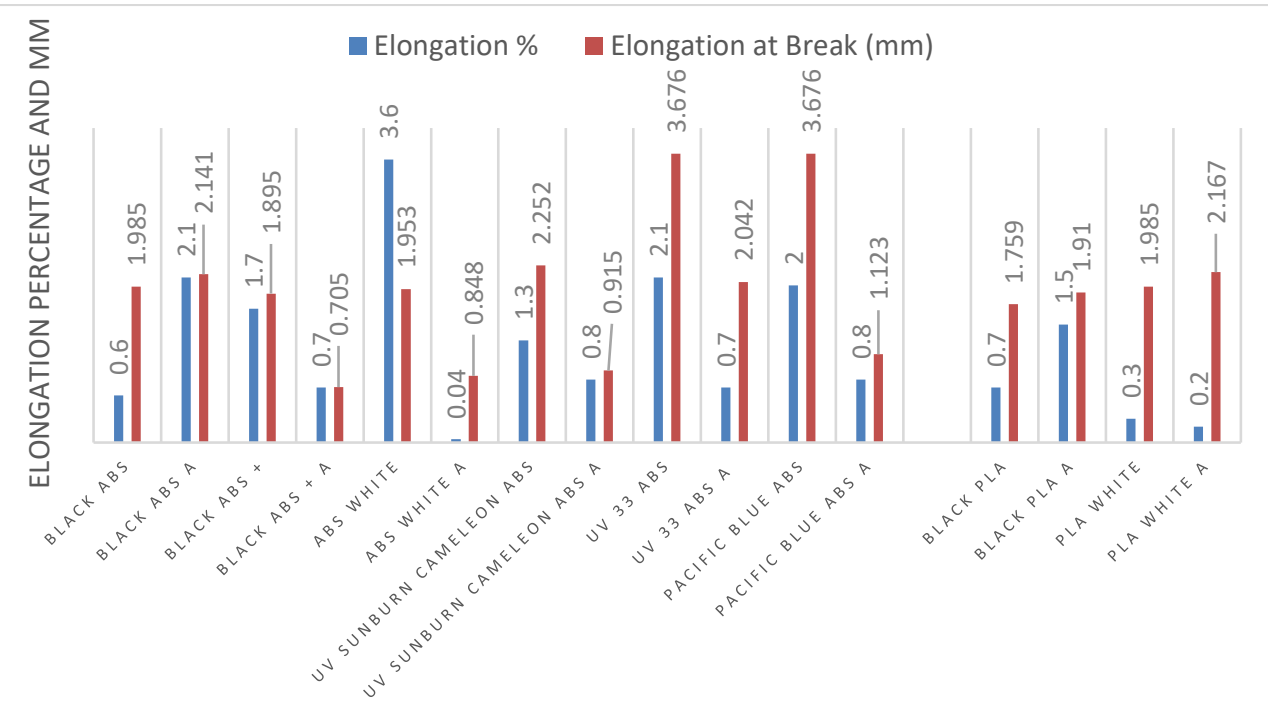

ALL SPECIMENS TESTED DURING FIRST EXPERIMENT

Figure 6: Ductility of experimental specimens in respect of the overall elongation and strain at breaking point. Specimens exposed to acetone are indicated by A (see online version for colour)

\subsection{Surface roughness properties}

The surface roughness of an area on an object indicates the texture value parameters - ie., how rough or smooth a specific surface is. Two main values are recorded for the purpose: the arithmetical mean roughness $(\mathrm{Ra})$ and the ten-point mean roughness $(\mathrm{Rz})$.

A simplified illustration is found below in Figure 7 , which displays how to obtain the surface roughness measurements according to the surface roughness standard (JIS B 0601-2001) [14]:

\begin{tabular}{|c|c|c|c|}
\hline Type & Symbol & How to Obtain & Explanation \\
\hline 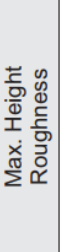 & $\mathrm{Rz}$ & $\begin{array}{l}\text { Ry is obtained from the distance in micron } \\
\text { meter between the highest peak and the } \\
\text { lowest valley in the range of sampled } \\
\text { reference length }(\ell) \text { to the direction of mean } \\
\text { line of the roughness curve. } \\
\qquad \mathrm{Rz}=\mathrm{Rp}+\mathrm{Rv}\end{array}$ & 8 \\
\hline 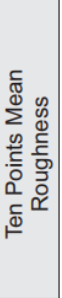 & RzJIS & $\begin{array}{l}\text { Rz is obtained from the total in micron meter } \\
\text { of the mean value of the each distance } \\
\text { between the mean line and } 5 \text { peaks }(Y p) \\
\text { from the highest one, and the mean value of } \\
\text { the each distance between the mean line } \\
\text { and the } 5 \text { valleys }(Y v) \text { from the lowest one, } \\
\text { of the roughness curve in the range of } \\
\text { sampled reference length " } \ell \text {. } \\
\text { RzJls = } \frac{\left(Y_{p 1}+Y_{p 2}+Y_{p 3}+Y_{p 4}+Y_{p 5}\right)+\left(Y_{v 1}+Y_{v 2}+Y_{v 3}+Y_{v 4}+Y_{v 5}\right)}{5}\end{array}$ & $\begin{array}{l}Y p 1, Y p 2, Y p 3, Y p 4, Y p 5: \\
\text { Distance from the mean line to highest } 5 \\
\text { peaks in the range of sampled reference } \\
\text { length " } p \text { " } \\
Y v 1, Y v 2, Y v 3, Y v 4, Y v 5 \text { : } \\
\text { Distance from the mean line to the lowest } 5 \\
\text { valleys in the range of sampled reference } \\
\text { length " } " \text { " }\end{array}$ \\
\hline 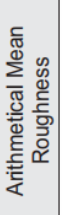 & $\mathrm{Ra}$ & $\begin{array}{l}\text { Ra is obtained from the following formula in } \\
\text { micron meter when the roughness curve is } \\
\text { expressed by } y=f(x) \text {, taking } X \text {-axis to the mean } \\
\text { line direction and } Y \text {-axis to the vertical } \\
\text { magnification of the roughness curve in the } \\
\text { range of sampled reference length " } ? \text {. } \\
\qquad R a=\frac{1}{\ell} \int_{0}^{\ell}\{f(x)\} d x\end{array}$ & ${ }^{r}$ \\
\hline
\end{tabular}

Figure 7: Derivation of roughness values by calculating the $R z$ and $R a$ values of surfaces are indicated, as found in the Surface Roughness standard (JIS B 0601-2001). 
Although the above illustrates how to obtain surface roughness values, current measuring instruments perform all of the calculations automatically. The specific gauge used for this experiment was a Domamoni AR-132B surface roughness tester from the Guangzhou Amittari Instruments Company.

The surface roughness profiles of the overall experimental specimens visibly declined with the exposure to acetone (Figure 8). Only the black PLA specimen set and the nylon composite set increased its surface roughness. The black PLA indicated almost no change from the original value.

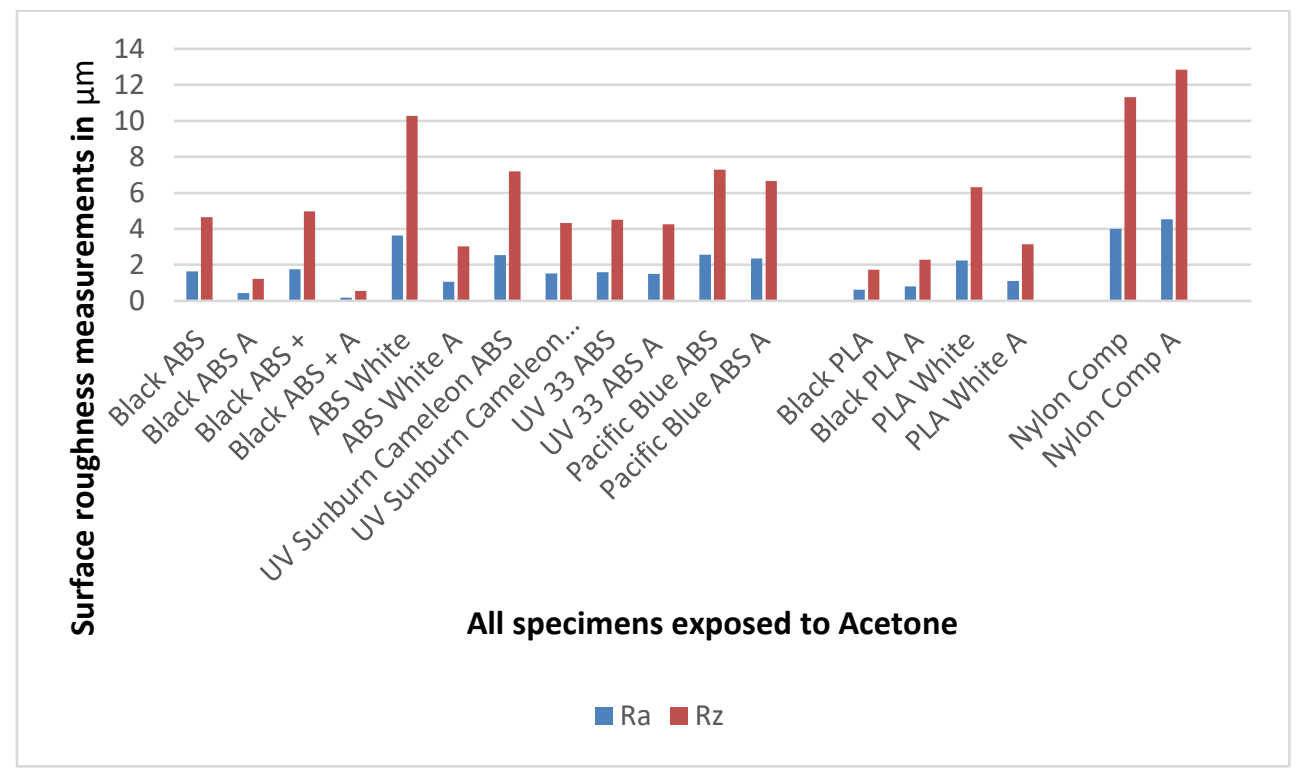

Figure 8: Effected surface roughness measurements of all experimental specimens; those exposed to acetone are indicated by A (see online version for colour)

The average Ra value of the control ABS specimens was $2.45 \mu \mathrm{m}$ and for the $\mathrm{Rz} 6.93 \mu \mathrm{m}$. The ABS specimens treated with acetone had an Ra value of $1.23 \mu \mathrm{m}$ and an Rz of $3.48 \mu \mathrm{m}$. The surface roughness therefore declined by fifty per cent after exposure to acetone. The average Ra value of the PLA specimens was $1.42 \mu \mathrm{m}$ and the corresponding Rz value was $4.02 \mu \mathrm{m}$. The PLA specimens that were exposed to acetone had an Ra value of $0.96 \mu \mathrm{m}$ and an Rz of $2.72 \mu \mathrm{m}$. Surprisingly, the surface roughness of the other experimental materials also declined; acetone was expected to affect the surface roughness of only ABS specimens. The average Ra value of the nylon alloy surface was $3.9 \mu \mathrm{m}$ and the Rz value was $11.31 \mu \mathrm{m}$. For the acetone-treated nylon alloy, the Ra was $4.54 \mu \mathrm{m}$ and the Rz was $12.83 \mu \mathrm{m}$.

\subsection{Lead time comparison for the production phase and the post-production phase}

Six industry experts were asked to supply the first author with computer assisted design (CAD) files so that their work could be reproduced on ELME machines. The aim was to compare high-end manufactured artefacts (EOS laser sintered) with entry-level reproductions (UP Mini material extrusion). When the lead times of the production phases and post-production finishing were compared, two very distinctive results were identified.

The first was the difference between the lead times of the production and post-production phases. The second was whether the post-production phase was viable or too time-consuming when compared with the production phase. Figure 9 illustrates these comparisons. It can be seen that four out of six artefacts required a shorter lead time during the post-production finishing phase. Only one-third of the post-production finishing times were longer than the production times. It is assumed that lead times would increase with more intricate artefact designs.

The total average production lead times were compared with those of the post-production finishing lead times. The average production time to create the artefacts was 54.5 hours; the average time 
to clean and apply surface finishing to the artefacts was 51.7 hours. Even though a third of the postproduction times were longer than the production times, the averages indicate that it took 3.5 hours less to complete PPFTs on the specimens.

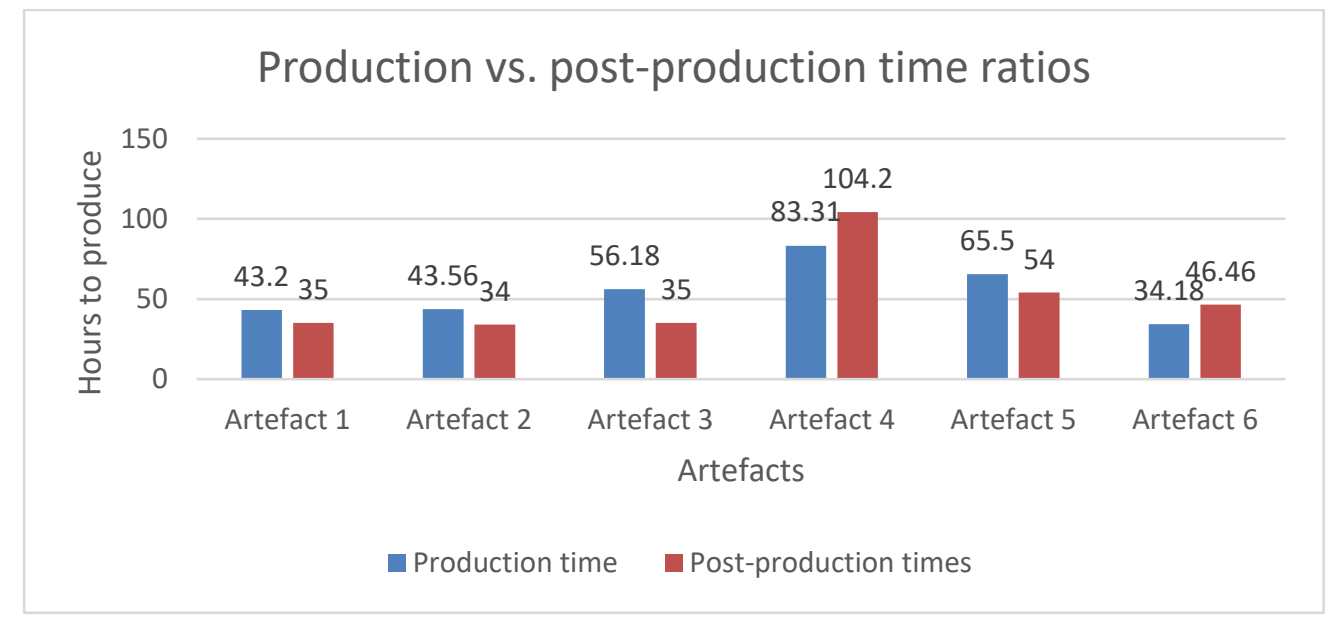

Figure 6: Lead time comparisons for the production and post-production phases of the six artefacts produced. The blue bars show the total number of hours to produce each artefact. The red bar corresponds to the total number of hours it took to post-process the artefacts. This includes clean-up, assembly, and surface finishing times. (see online version for colour)

\section{DISCUSSION}

This paper provides evidence that developing acetone finishing techniques could narrow the gap between ELME and high-end additive manufacturing. By doing so, a larger spectrum of prosumers will then be able to apply this technology, using manufacturing and training facilities such as the I2P laboratories. This process, in turn, can be developed through sustainable hard-skills training programmes that address technique development. This practice could advance the ELME technology to stimulate the creation of a niche market, where previously reluctant prosumers will now be able to produce entry-level $A M$ artefacts at relatively low cost, in comparison with high-end additive manufacturing.

It can be argued that the hard-skills development of PPFTs can be seen as an indirect solution to deal with problematic areas such as prolonged production times in high-end additive manufacturing, and to address the inadequate surface quality of products. A recent study investigated the mechanical properties of PLA and ABS, which indicated that ELME-produced artefacts can perform equally as well as high-end 3D printed extrusion material [9]. Due to the lack of post-production development, improvements are currently only seen on ELME during the production phase. The reason that this kind of investigation has not expanded into the post-production phase may be found in the lack of PPFTs skill development.

The limitations of conventional materials indicate that PPFTs offer an alternative way to increase the value of their output and quality in terms of their tensile, surface profile and ductile properties. The results presented here, however, show that the tensile strength of ABS specimens declines when they are exposed to acetone, while their ductility increases. The surface roughness decreased after acetone exposure, indicating that PPFTs should be adopted and developed for a post-production phase, depending on the parts' purpose or functionality. A functional object will need increased ductility, whereas an aesthetically pleasing, smoothed artefact might not need tensile strength to be a feature.

The lead times for PPFTs were less than the actual production phase, confounding the notion that PPFTs involve a laborious time-consuming process. Indeed, it takes less time to clean and surface finish than to produce the artefacts. Research should focus on finding a resolution of these limitations by thinking beyond the scope of the pre-production phase and the production phase [7]. 
This study has demonstrated that acetone has a significant influence - both adverse and favourable - on the mechanical properties of thermoplastics used for ELME production. The usefulness of acetone has clearly been indicated in the post-processing stage of ELME manufacturing, as a motivation for its inclusion in the low-cost 3D printing industry.

The study furthermore corroborates findings of other research conducted by authors such as Galantucci et al. [8], Pearce [16], and Tanikella et al. [19]. Exposure to acetone reduces tensile strength in ABS plastics, although our study recorded that it increased the UTS of some PLA specimens - a result not recorded in the existing academic literature. The increased ductility of reduced-UTS specimens can be an advantage for functional-object applications in mechanical components.

Convincing evidence is presented through the results to validate that acetone can be used successfully for post-processing in ELME fabrication. It has a notable influence on the quality of ELME artefacts which, if implemented as a PPFT, could lead to the development of a low-cost niche market previously excluded from additive manufacturing. Its inclusion will facilitate the successful production of improved quality for entry-level additive manufacturing to reduce cost and production waste.

Further research is recommended to develop hard-skills techniques for implementing the use of acetone for ELME thermoplastics in AM. A comparison with High-end Material Extrusion (HeME) specimens exposed to acetone should also be considered.

\section{REFERENCE}

[1] Cantrell, J., Rohde, S., Damiani, D., Gurnani, R., DiSandro, L., Anton, J., Young, A., Jerez, A., Steinbach, D., Kroese, C. \& Ifju, P. 2016 Experimental characterization of the mechanical properties of 3D-printed $A B S$ and polycarbonate parts. Available:

http://cimar.mae.ufl.edu/rapid_proto/pages/3D\%20Printing\%20Paper\%20Final\%20Manuscript.pdf [Accessed on 24 July 2017].

[2] Campbell, R.I., Martorelli, M. \& Lee, H.S. 2002. Surface roughness visualisation for rapid prototyping models. Computer-Aided Design, 34, pp. 717-725.

[3] Campbell, R.I., de Beer, D.J. \& Pei, E. 2011. Additive manufacturing in South Africa: Building on the foundations, Rapid Prototyping Journal, 17(2), pp. 156-162.

[4] Chulilla-Cano, J.L. 2011. The Cambrian explosion of popular 3D printing, International Journal of Interactive Multimedia and Artificial Intelligence, 1(4), pp. 30-32.

[5] de Beer, D.J. \& Campbell, R.I. 2016. Using Idea 2 Product Labs ${ }^{\circledast}$ as a strategy for accelerating technology transfer, International Journal of Technology Transfer and Commercialisation, 14(3/4) pp. 249-261. DOI: 10.1504/IJTTC.2016.10002948.

[6] de Bruijn, E., O'Callaghan, R., Ribbers, P., de Jong, J. \& von Hippel, E.A. 2010. On the viability of the open source development model for the design of physical objects: Lessons learned from the RepRap project. MSc thesis, University of Tilburg, The Netherlands.

[7] Fernandez-Vicente, M., Canyada, M. \& Conejero, A. 2015. Identifying limitations for design for manufacturing with desktop FFF 3D printers, Int. J. Rapid Manufacturing, 5(1), pp. 116-128.

[8] Galantucci, L.M., Lavecchia, F. \& Percoco, G. 2010. Quantitative analysis of a chemical treatment to reduce roughness of parts fabricated using fused deposition modeling, CIRP Annals - Manufacturing Technology, 59(1), pp. 247-250.

[9] Havenga, S., de Beer, D.J., van Tonder, P.J.M., \& Campbell, R.I. 2015. Effectiveness of acetone postproduction finishing on entry level FDM printed ABS artefacts. RAPDASA Conference Proceedings 2015. ISBN: 978-0-620-66820-0 (e-book).

[10] Kreiger M. \& Pearce, J.M. 2013. Environmental impacts of distributed manufacturing from 3-D printing of polymer components and products, in Symposium D/G - Materials for Sustainable Development Challenges and Opportunities. DOI: 1557/op0130.11.2.319

[11] Kreiger M. \& Pearce, J.M. 2013. Environmental impacts of distributed manufacturing from 3-D printing of polymer components and products. MRS Online Proceedings Library, 1492, mrsf12-1492-g01-02. Revised edition.

[12] Letcher, T., Rankouhi, B. \& Javadpour, S. 2015. Experimental study of mechanical properties of additively manufactured ABS plastic as a function of layer parameters. In ASME 2015 International Mechanical Engineering Congress and Exposition (pp. V02AT02A018-V02AT02A018). American Society of Mechanical Engineers. 
[13] Mohomed, I. \& Dutta, P. 2015. The age of DIY and dawn of the maker movement, ACM SIGMOBILE Mobile Computing and Communications Review, 18(4), pp. 41-43.

[14] Mokuji, S. 2001. Surface roughness standard (JIS B 0601-2001). Available from: http: / / files.engineering.com/download.aspx?folder=1d149e35-945a-4839-9ef33162af3752f4\&file=Binder2.pdf [Accessed on 28 December 2017].

[15] Mota, C. 2011. The rise of personal fabrication, in Proceedings of the 8th ACM Conference on Creativity and Cognition, New York, NY, USA, pp. 279-288.

[16] Pearce, J.M. 2015. A novel approach to obviousness: An algorithm for identifying prior art concerning 3-D printing material. World Patent Information 42, pp. 13-18. doi:10.1016/j.wpi.2015.07.003.

[17] Pearce, J.M., Blair, C.M., Laciak, K.J., Andrews, R., Nosrat, A. \& Zelenika-Zovko, I. 2010. 3-D printing of open source appropriate technologies for self-directed sustainable development, J. Sustain. Dev. 3(4), p. 17-29.

[18] Rosas, L. 2013. Characterization of parametric internal structures for components built by fused deposition modeling, University of Windsor. Electronic Theses and Dissertations. 4763

[19] Tanikella, N.G., Wittbrodt, B. \& Pearce, J.M. 2016. Tensile strength of commercial polymer materials for fused filament fabrication 3-D printing. Available from: https://www.academia.edu/26772825/Tensile_Strength_of_Commercial_Polymer_Materials_for_Fused_F ilament_Fabrication_3-D_Printing?auto=view\&campaign=weekly _digest [Accessed on July 2016].

[20] South African Bureau of Standards. 2012. Plastics - Determination of tensile properties - Part 2: Test conditions for moulding and extrusion plastics (ISO 527-2:2012). Available from: http: / /www.iso.org/iso/catalogue_detail.htm?csnumber $=56046$.

[21] Tymrak, B.M., Kreiger, M. \& Pearce, J.M. 2014. Mechanical properties of components fabricated with open-source 3-D printers under realistic environmental conditions, Mater. Des. 58, pp. 242-246.

[22] Wittbrodt, B.T., Glover, A.G., Laureto, J., Anzalone, G.C., Oppliger, D., Irwin, J.L. \& Pearce, J.M. 2013. Life-cycle economic analysis of distributed manufacturing with open-source 3-D printers, Mechatronics, 23(6), pp. 713-726. 